- Occasionally, pathological sinuses in the maxillofacial region can be due to retained foreign bodies.

- Foreign bodies induce reparative granuloma formation making their detection by the naked eye difficult during surgery.

- Radiolucent foreign bodies like wood evade detection by X-rays.

- Performing ultrasounds and injecting dye into the sinus are useful for detection and location of wooden foreign bodies in soft tissues.

\title{
Recurrent sinus of the cheek due to a retained foreign body: report of an unusual case
}

\author{
A. Auluck, ${ }^{1}$ A. G. Behanan, ${ }^{2}$ K. M. Pai ${ }^{3}$ and C. Shetty ${ }^{4}$
}

\begin{abstract}
Pathological sinuses in the maxillofacial region are frequently encountered in clinical practice. These sinuses may be a sequelae of periapical and periodontal pathologies or infections like osteomyelitis, actinomycosis etc. Classical clinical symptoms and radiographic features accompany all these infections. Rarely, sinuses in the oro-facial region can be sequelae of retained occult foreign bodies like wood in the soft tissues. We report a case of recurrent sinus of the cheek caused by an occult wooden splinter and discuss its diagnosis and clinical management.
\end{abstract}

\begin{abstract}
INTRODUCTION
Foreign bodies can penetrate soft tissues through open wounds and lacerations sustained during trauma or by direct impact against them. Such wounds harbouring foreign bodies may appear to be deceptively minor and may not be accompanied by any major symptoms. But if these foreign bodies are left undetected in the tissues they can result in serious sequelae days, months or even years after initial trauma. ${ }^{1}$ The purpose of reporting this unusual case of recurrent sinus of the cheek caused by a retained wooden splinter is to highlight the difficulties in detection of foreign bodies and discuss its clinical management. We also discuss the usefulness of various imaging modalities and emphasise the importance of performing ultrasound examinations on patients with injuries caused by wooden splinters.
\end{abstract}

\footnotetext{
1*Postgraduate Student, Oral Medicine and Radiology, Manipal College of Dental Sciences, Manipal-576104, Karnataka, India; ${ }^{2-3}$ Professors, Manipal College of Dental Sciences, Manipal-576104, Karnataka, India. ${ }^{4}$ Associate

Professor, Kasturba Medical College, India

${ }^{*}$ Correspondence to: Dr Ajit Auluck

Email:drajitauluck@yahoo.co.in
}

\section{Refereed Paper}

Received 16.02.04; Accepted 11.08.04

doi: $10.1038 /$ sj.bdj.4812172

๑ British Dental Journal 2005; 198: 337-339

\section{CASE REPORT}

A 31-year-old man presented at our hospital complaining of a sinus in the right cheek. His history included an accidental fall from a bicycle 38 days previously, resulting in a sharp wooden splinter piercing his face. He tried to remove the foreign body immediately after the injury. In the attempt he only partly succeeded and a piece of the splinter fractured and remained embedded in the soft tissues. He then visited a general dental practitioner who was unable to detect any foreign body and assured the patient that the entire wooden piece was removed. The dentist dressed and sutured the wound and prescribed antibiotics, analgesics and a tetanus toxoid injection without performing any other investigations. Three weeks after this treatment, a small painful diffuse swelling with a draining sinus appeared near the right angle of the mandible. The swelling was located below the original site of the injury (Table 1, Day 23). The patient revisited his dentist for this tender swelling, who performed an incision and drainage procedure and recommended antibiotics.

Two weeks after the treatment by his dentist (Day 38 after the initial injury), the patient again developed a swelling with a sinus opening at a new site near the pre- molar region. At this stage he reported at our hospital for further consultation and treatment.

The patient was healthy with vital signs within normal limits. Extra-oral examination revealed a diffuse swelling of $3 \times 4 \mathrm{~cm}$ on the right side of the face extending from the angle of the mandible to the corner of the mouth (Fig. 1). The skin over the swelling was smooth; shiny with a solitary draining sinus at the premolar region and a scar near the angle of mandible. On palpation, the right submandibular lymph nodes were tender and mobile. Intra-oral examination failed to reveal any abnormality in dental or periodontal tissues. Based on the history and clinical presentation a differential diagnosis of a sinus related to a retained foreign body or persisting infection were considered and radiographs were ordered.

Periapical and panoramic radiographs (Fig 2) failed to reveal the presence of any wooden splinter but excluded the possibility of any dental or periodontal foci of infection as the cause of sinus. Haematological investigations were advised, which yielded normal values except total WBC count, which had increased to 13,000 cells $\mathrm{cmm}^{-1}$ (normal 4,000-11,000 cells $\mathrm{cmm}^{-1}$ ).

A surgical exploration of the draining solitary sinus was performed (on Day 38) 


\section{PRACTICE}

\begin{tabular}{|c|c|c|}
\hline DAY 1 & $\begin{array}{l}\text { Accidental trauma with penetration of } \\
\text { wood into the cheek }\end{array}$ & $\begin{array}{l}\text { Dressing and wound sutured. No investigations, } \\
\text { antibiotic, }{ }^{*} \text { analgesic }{ }^{* *} \text { and tetanus toxoid }\end{array}$ \\
\hline DAY 23 & $\begin{array}{l}\text { Painful swelling with sinus near the angle } \\
\text { at a site below the site of original injury }\end{array}$ & Incision and drainage, antibiotic ${ }^{*}$ \\
\hline $\begin{array}{l}\text { DAY } 38 \text { (Reported } \\
\text { to our hospital) }\end{array}$ & $\begin{array}{l}\text { Diffuse swelling with draining sinus in } \\
\text { the right premolar region }\end{array}$ & $\begin{array}{l}\text { IOPA, OPG not revealed any foci of infection, } \\
\text { surgical debridement and antibiotic }\end{array}$ \\
\hline DAY 81 & $\begin{array}{l}\text { Diffuse swelling with a sinus in the right } \\
\text { molar region }\end{array}$ & $\begin{array}{l}\text { US revealed hyper echoic region surrounded by } \\
\text { a hypo echoic halo suggestive of foreign body }\end{array}$ \\
\hline DAY 85 & $\begin{array}{l}\text { Surgical treatment under GA and wood } \\
\text { piece was removed }\end{array}$ & $\begin{array}{l}\text { Antibiotic*and metronidazole } 400 \mathrm{mg} \text {. } \\
\text { Analgesic** }\end{array}$ \\
\hline DAY 90 & Patient discharged & Follow up to date uneventful \\
\hline
\end{tabular}

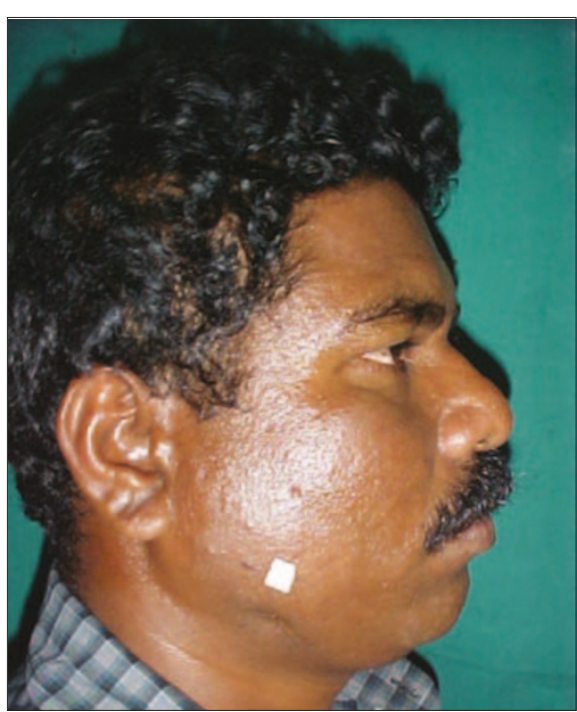

Fig. 1 Extra-oral examination revealed a diffuse swelling of $3^{\prime} 4 \mathrm{~cm}$ on the right side of the face extending from the angle of the mandible to the corner of the mouth

under local anaesthesia to eliminate any wooden splinter or a nidus of infection, which can impair healing. The pus from the site was sent for culture that grew streptococcus viridians. The wound was surgically explored but still no wooden foreign body was detected. Further progression of the case and treatment is given in Table 1.

Six weeks after the first treatment at our hospital (Day 81 after the initial injury), the patient developed a swelling again with a new sinus posterior to the previous sinus opening near the molar region. We decided to perform an ultrasound examination to check if there was a contained collection of pus or diffuse involvement of the soft tis-

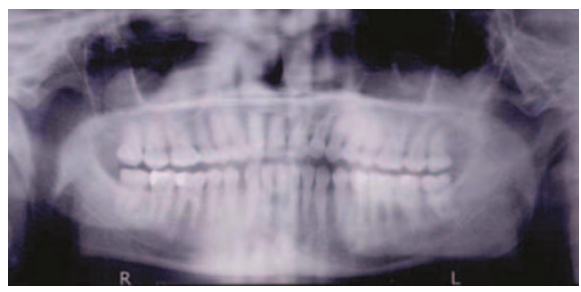

Fig. 2 Panoramic radiograph showing no evidence of any foreign wooden body

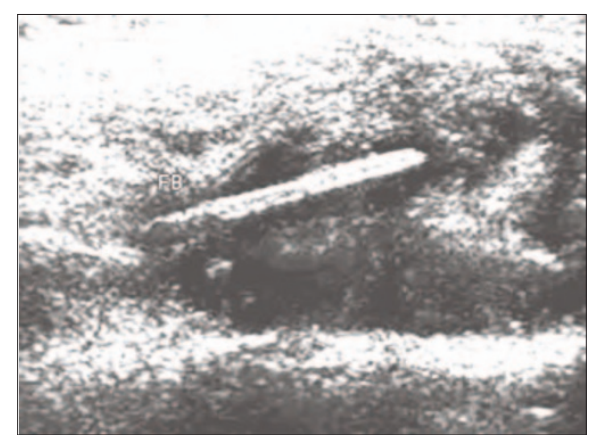

Fig. 3 Ultrasound showing (a) hyper echoic region, surrounded by (b) hypo echoic halo

sues. As it was a soft tissue injury, and the only known foreign body was a piece of wood, ultrasound was preferred in favour of a CT scan. Ultrasound examination revealed a hyper echoic region of $1.8 \mathrm{~cm}$ surrounded by a hypo echoic zone in the cheek (Fig. 3) suggestive of a retained foreign body. The patient was hospitalised for surgery under general anesthesia to remove the foreign body.

After making a submandibular incision, the muscles were dissected in layers. The wooden foreign body was not readily detected, still eluding detection. Therefore, methylene blue dye was injected into the sinus opening to track the course of the sinus and detect the point of its origin. The sinus tract was found to originate from the region below the masseter muscle. On closer inspection, a fibrous capsule was detected which on exploration yielded the wooden splinter (Fig. 4). The wooden splinter was subsequently removed and the wound was cleaned, debrided, irrigated with betadine and sutured. Post-operatively antibiotics (Amoxicillin $500 \mathrm{mg}$ TID $\times$ five days) and anti-inflammatory analgesics (Ibuprofen $400 \mathrm{mg}$ TID $\times$ five days) were prescribed. Follow up to date, one year after the surgery has been uneventful.

\section{DISCUSSION}

Wood acting as a foreign body and complications arising due to retained wooden splinters like abscess, fistula formation or necrotising fasciitis have been reported in the literature. ${ }^{1-3}$ Wood, because of its organic nature and porosity provides a good medium for microbial agents like clostridium tetani. ${ }^{1,2}$ Wood is soft, can fragment easily with minimal force and evades detection due to its radiolucent nature. Such properties of wood make it potentially lethal. Therefore, an early detection and removal of wooden foreign particles from soft tissues is essential.

Embedded foreign bodies induce a reparative granuloma formation, which surrounds them, making their detection by the naked eye difficult during surgery. This fact explains the failure to detect the wooden foreign body in spite of several surgical interventions. This also emphasises the need for performing an ultrasound as a preferred imaging modality for detection of wooden foreign bodies in soft tissues.

Visibility of materials on plain radiographs depends on their ability to absorb $\mathrm{X}$-rays, their density and the difference in density between them and the tissue in which they are embedded. Since wood has a low density, plain radiographs are unable to detect wooden foreign bodies in soft tissues. ${ }^{4,5}$ Hence, in our case periapical and panoramic radiographs (Fig. 2) failed to detect the presence of a wooden splinter in the cheek.

Computed tomography is the imaging modality of choice for detection of the majority of foreign bodies. ${ }^{1,2}$ But in the detection of wooden foreign particles, the role of a CT scan is limited. Wood is an organic material with low density almost like that of soft tissues. ${ }^{6}$ Therefore, it can be mistaken for a gas bubble or air in the anatomical sinuses. ${ }^{1,4,7,8}$. Moreover, CT scan patterns of wood are variable. The image pattern can mimic a gas bubble or a bone fragment. ${ }^{1,7}$ Variability in appearance of the wood on a CT scan not only depends on the varieties of wood but also depends on the freshness and dryness of wooden splinters. Dry wood is porous while fresh wood has capillaries, which cause differences in their densities. ${ }^{7}$ It is believed that after 48 hours in an aqueous environment, the wooden foreign body absorbs water and its density increases. ${ }^{6}$ Therefore, dry wood can be detected after some time as it absorbs water from the surrounding tissues. ${ }^{1,6}$ Hence a delayed CT scan detects the wooden splinter better and in acute cases where a CT scan can fail to detect their presence. However, in our patient an ultrasound was preferred over a CT scan.

MRI is used for better visualisation of the soft tissues. The technique is based on behaviour of protons in the magnetic field; materials with water content can be more easily detected than those without it. 


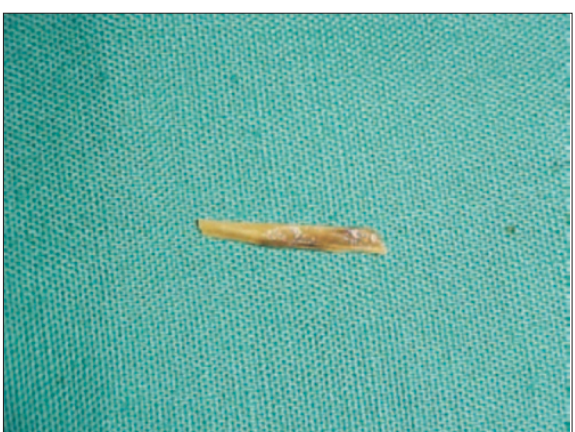

Fig. 4 Wooden foreign body of $1.8 \mathrm{~cm}$ removed from the patient's cheek

Therefore MRI cannot detect dry wooden splinters. Furthermore, a CT scan is demonstrated to be superior to MRI in the detection of wooden foreign bodies. ${ }^{1,4,6,8}$ Hence, the role of MRI in the detection of wooden foreign bodies is limited and was not considered for our patient.

Reports suggest that ultrasound is a superior and better imaging modality than CT scan and MRI for foreign body detection in soft tissues. ${ }^{4,5,9,10}$ Ultrasound is both sensitive and specific in detecting wooden foreign bodies. ${ }^{4,10}$ On an ultrasound, wood appears hyper echoic with no reverberations or acoustic shadowing. ${ }^{4}$ In our case an ultrasound assisted in the detection of an occult wooden foreign body in the cheek. Therefore, performing ultrasound, injecting the dye into the sinus tract followed by surgery made the detection and removal of the wooden foreign particle in our patient successful. In addition, ultrasound is simple and less expensive which makes it a preferred imaging modality for detection of wooden foreign bodies in soft tissues.

Routinely dentists do not request ultrasound examinations. Although rare, patients with maxillofacial injuries caused by wooden splinters can approach dentists for initial treatment. Therefore awareness of the usefulness of ultrasounds in detection of foreign bodies in soft tissues is of considerable interest to dentists for prompt treatment.

In conclusion, ultrasound examinations should be performed on all patients with suspected or known wood injuries for early detection and prompt treatment.

We would like to acknowledge Dr K. S. Bhat for his guidance and important advice in writing this article.

1. Vanderwal K G H, Bourkes R J. Intra-orbital bamboo foreign body in a chronic stage - A case report. Int $\rfloor$ Oral Maxillofac Surg 2000; 29: 428-429.
2. Akuner M, Ajay A, Top H. A case of self-inflicted intra-orbital injury: Wooden foreign body introduced into the ethmoidal sinus. Ann Plast Surg 1998; 41: 422-424.

3. Yanay O, Vaughan D J, Diab M, Brownstein D, Brogan TV. Retained wooden foreign body in a child's thigh complicated by severe necrotizing fasciitis - A case report and discussion of imaging modalities for early diagnosis. Pediatr Emerg Care 2001; 17: 354-355.

4. Oikarinen KS, Nieminen T M, Makarauren $\mathrm{H}_{\text {, }}$ Pyhtinen J. Visibility of foreign bodies in soft tissue in plain radiographs, computed tomography, magnetic resonance imaging and ultrasound. An in vitro study. Int J Oral Maxillofac Surg 1993; 22: 119-124.

5. Graham D D. Ultrasound in the emergency department: Detection of wooden foreign bodies in soft tissues. J Emerg Med 2002; 22: 75-79.

6. Hansen J E, Gudeman S K, Holgate R C, Saunders R A. Penetrating intracranial wood wounds: clinical limitations of computed tomography. J Neurosurg 1988; 68: 752-756.

7. Pythinen J, Ilkko G, Ladhe $\mathrm{S}$. Wooden foreign bodies in CT. Case reports and experimental studies. Acta Radiol 1995: 36: 148-151.

8. Krimmel M, Cornelius C P, Stojadinovic S, Hoffmann J, Reinerts. Wooden foreign bodies in facial injury: A radiological pitfall. Int J Oral Maxillofac Surg 2001; 30: 445-447.

9. Ng S Y, Songra A K, Bradley P F. A new approach using intra-operative ultrasound imaging for the localization and removal of multiple foreign bodies in the neck. Int J Oral Maxillofac Surg 2003; 32: 433-436.

10. Jacobson J A, Powell A, Craig J G, Bouffard J A, Van Hobsbeeck M T. Wooden foreign bodies in soft tissue - detection by US. Radiology 1998; 206: 45-48. 